\title{
Do Physical Capacity and Interchange Rest Periods Influence Match Exercise-Intensity Profile in Australian Football?
}

\author{
Mitchell Mooney, Stuart Cormack, Brendan O'Brien, and Aaron J Coutts
}

\begin{abstract}
Purpose: The purpose of this study was to determine if Yo-Yo Intermittent Recovery level 2 (Yo-Yo IR2) and the number of interchange rotations affected the match activity profile of elite Australian footballers. Method: Fifteen elite Australian footballers completed the Yo-Yo IR2 before the beginning of the season and played across 22 matches in which match activity profiles were measured via microtechnology devices containing a global positioning system (GPS) and accelerometer. An interchange rotation was counted when a player left the field and was replaced with another player. Yo-Yo IR2 results were further split into high and low groups. Results: Players match speed decreased from 1st to 4th quarter, while average-speed $(\mathrm{m} / \mathrm{min}: P=.05)$ and low-speed activity (LSA, $<15 \mathrm{~km} / \mathrm{h}$ ) per minute (LSA m/min; $P=.06$ ) significantly decreased in the 2nd half. Yo-Yo IR2 influenced the amount of $\mathrm{m} / \mathrm{min}$, high-speed running (HSR, $>15 \mathrm{~km} / \mathrm{h}$ ) per minute (HSR $\mathrm{m} / \mathrm{min}$ ) and accelerometer load/min throughout the entire match. The number of interchanges significantly influenced the HSR $\mathrm{m} / \mathrm{min}$ and $\mathrm{m} / \mathrm{min}$ throughout the match except in the 2nd quarter. Furthermore, the low Yo-Yo IR2 group had significantly less LSA m/min in the 4th quarter than the high Yo-Yo IR2 group (92.2 vs $96.7 \mathrm{~m} /$ min, $P=.06$ ). Conclusions: Both the Yo-Yo IR2 and number of interchanges contribute to $\mathrm{m} / \mathrm{min}$ and HSR $\mathrm{m} /$ min produced by elite Australian footballers, affecting their match activity. However, while it appears that improved Yo-Yo IR2 performance prevents reductions in LSA $\mathrm{m} / \mathrm{min}$ during a match, higher-speed activities (HSR $\mathrm{m} / \mathrm{min}$ ) and overall physical activity $(\mathrm{m} / \mathrm{min}$ and $\mathrm{load} / \mathrm{min}$ ) are still reduced in the 4th quarter compared with the 1st quarter.
\end{abstract}

Keywords: Yo-Yo Intermittent Recovery Test, substitution, high-speed running

Australian football is a field-based team sport that requires high-intensity, intermittent exercise including many intense activities (ie, accelerations, decelerations, tackling, collisions, sprinting, change of direction, etc). These match demands elicit high levels of fatigue in players that have been shown through reductions in player activity profiles. ${ }^{1,2}$ While it is generally understood that many factors influence performance in Australian football (player quality, tactical strategy, skill execution, etc), a major focus for most clubs is to develop physical capacities and tactical systems that provide their players with the capacity to maintain higher exercise intensity toward the end of the game. Two of the obvious methods for achieving this are improving the physical capacity of

Mooney is with Movement Sciences, Australian Institute of Sport, Bruce, ACT, Australia. Cormack is with the School of Exercise Science, Australian Catholic University, Melbourne, Australia. O'Brien is with the School of Health Sciences, University of Ballarat, Ballarat, Australia. Coutts is with the Sport and Exercise Discipline Group, University of Technology Sydney, Sydney, Australia. players through specific training and employing tactical strategies such as using player interchange to provide regular recovery opportunities during matches. However, despite the general assumption that both approaches contribute to improved physical performance, to date there has been little scientific research examining the relationships between players' physical capacity and player interchange on match activity profiles in elite Australian football.

Several studies have shown that player match activity profiles are reduced as Australian football matches progress. ${ }^{1-3}$ For example, Coutts et $\mathrm{al}^{1}$ reported a large reduction in both overall match speed and higher-speed running (HSR; $>14.4 \mathrm{~km} / \mathrm{h}$ ) from the first to the fourth quarters of matches in professional Australian football players from a team ranked in the bottom $25 \%$ of the competition. In addition, it was reported that players reduced their lower-intensity activities as the matches progressed, possibly as a form of pacing to retain the ability to exercise at higher intensity when required to. More recently, Aughey ${ }^{3}$ reported a moderate reduction in the number of maximal accelerations (efforts 2.78-10.00 $\mathrm{m} / \mathrm{s}^{2}$ ) and a small reduction in the distances traveled at 
higher speeds ( $>14.9 \mathrm{~km} / \mathrm{h}$ ) during professional Australian football matches. However, in contrast to the aforementioned study, ${ }^{1}$ these investigators did not observe any changes in the activity profile at lower speeds, and it was suggested that improved physical capacities of the players in the higher-ranked team explained these differences. Unfortunately, the fitness characteristics of these 2 teams were not reported, and analysis of this suggestion is not possible. While it is tempting to speculate that improved fitness characteristics affect the match activity profile of professional Australian football players, at present the relationship between specific fitness qualities and the match activity profile of professional Australian football players remains unclear.

Much of the focus of physical training in professional Australian football players is on the development of specific fitness capacities that allow improved physical performance during competition, which is based on previous findings in Australian football that HSR is positively associated with performance. ${ }^{4}$ For example, it has recently been demonstrated that professional Australian football players who performed better on the Yo-Yo Intermittent Recovery Test level 2 (Yo-Yo IR2) had an increased ability to gain more disposals of the ball during matches, and this was mediated through increased HSR $(>15 \mathrm{~km} / \mathrm{h}){ }^{4}{ }^{4}$ These results suggest that focus on improving the Yo-Yo IR2 performance capacity of professional Australian football players can improve their involvement with the ball. However, the direct relationship between improved physical capacity and improved playing performance is less clear. Other researchers have shown that higher-caliber Australian football players had a lower physical activity profile during matches but increased involvement with ball (ie, kicks, handballs, total disposals) than lower-caliber players on the same team. ${ }^{5}$

Over the past decade, there has been increased use of the interchange bench as a tactical strategy to manage player work demands and to provide players with opportunities for rest to cope with the running requirements of the sport. Indeed, in 2003, teams made fewer than 30 player interchanges during games, but they made more than 120 interchanges per game in 2011 despite rule modifications attempting to limit this (data obtained from CIA software, Champion Data, Southbank, Australia). Depending on position within a team, players are now usually provided 0 to 10 interchanges per game (ranging from $43 \mathrm{~s}$ to $8.5 \mathrm{~min}$ each) in addition to the quartertime, 3-quarter-time, and halftime breaks (unpublished observation, 2010). These breaks provide increased opportunities for fluid, electrolyte, and carbohydrate ingestion and passive rest, which may delay fatigue and increase the capacity for higher-intensity exercise. ${ }^{6.7} \mathrm{It}$ is widely accepted the increase in frequency of rest periods during matches has contributed to the increased physical activity profiles currently observed in Australian football. At present, however, there have been no published studies that have examined the associations between player interchange and physical activity outputs in professional Australian football.
The purpose of this study was to determine if there is evidence of reduced exercise intensity across Australian football matches and to determine if physical capacity (ie, Yo-Yo IR2) or the number of interchange rotations affects match exercise intensity.

\section{Methods}

\section{Participants}

Fifteen elite Australian footballers from the same team participated in this study. The players had a mean \pm SD height of $186.1 \pm 6.5 \mathrm{~cm}$, mass of $84.3 \pm 8.3 \mathrm{~kg}$, and age of $22.6 \pm 3.2$ years. Informed consent was gathered before the commencement of the study. Ethical approval was obtained by the university research ethics committee.

\section{Design}

This study was a prospective analysis across an entire 22-match elite Australian Football League season.

\section{Methodology}

Participants were required to perform the Yo-Yo IR2 less than 10 days before the first match of the regular season. All performed the test on the same indoor surface. Each participant had completed this test previously and was familiar with the procedures. This procedure has been described in detail elsewhere, with typical errors ranging from $4.9 \%$ to $10.4 \%$ for a variety of sports and standards. ${ }^{8}$ Players were allocated into high and low groups based on Yo-Yo IR2 score using median split technique. After the test, participants underwent 1 week of their regular training before the commencement of the season. A typical training week ( $7 \mathrm{~d}$ between matches) would consist of day 1 , recovery (aquatic mobility); day 2 , active mobility and flexibility with light skills training; day 3 , skills training and weights; day 4 , day off; day 5 , skills training and weights; day 6 , light skills session; and day 7 , match. Yo-Yo IR2 performance has shown not to significantly fluctuate between the beginning and the end of the season in elite soccer players. ${ }^{9}$ Given that Australian football and soccer share similarities in training stimulus (ie, the match is the greatest stimulus during the training week) that is of a similar magnitude (ie, distance covered), it is reasonable to assume that these results are comparable in Australian football.

All participants had their match activity profiles recorded by a portable GPS unit sampling at $5 \mathrm{~Hz}$ while the internal accelerometer (housed inside the GPS device) sampled at $100 \mathrm{~Hz}$ (MinimaxX, Team 2.5, Catapult Innovations, Scoresby, Australia). Match activity profiles were gathered throughout the entire 22-match season. Each player recorded 1 to 4 activity profiles for the season. GPS and accelerometer data were downloaded postmatch using manufacturer-specific software (Logan Plus version 4.4.0) for analysis. 
Variables collected from GPS were distance traveled per minute $(\mathrm{m} / \mathrm{min})$; distance traveled at HSR per minute (HSR $\mathrm{m} / \mathrm{min}$ ), where HSR $\mathrm{m}$ were the distance traveled at $>15 \mathrm{~km} / \mathrm{h}$; lower speed activity (LSA) distance traveled at $<15 \mathrm{~km} / \mathrm{h}$ per minute; HSR as a percentage of total distance (\%HSR); and accelerometer load $/ \mathrm{min}$. Load $/ \mathrm{min}$ is the root of the sum of the squares of the magnitude of the 3 acceleration vectors (mediolateral, anteroposterior, and vertical) divided by playing duration, as described in detail previously. ${ }^{4}$ These variables have been tested for reliability and validity: HSR activities (striding and sprinting) coefficient of variation (CV) $=9.0 \%$ to $11.9 \%$ (activity dependent), validity range $-6.2 \%$ to $4.6 \%$ from actual distance (activity dependent), ${ }^{10}$ while load/min has shown a CV of $<2 \%$. ${ }^{11}$ The number of interchanges that occurred per player was recorded as the number of times the player was not participating as one of the active 18 players on the field.

\section{Statistical Analysis}

One-way analysis of variance (ANOVA) was performed to determine the time effect (difference between quarters) of all match exercise-intensity variables. A 2-way ANOVA was performed to identify effects by quarter and by capacity (Yo-Yo IR2). Multivariate linear-regression analysis was performed with Yo-Yo IR2 and number of interchanges used to predict match-intensity variables for all 4 quarters. Tukey post hoc analysis was performed to identify significant differences between conditions. Multivariate linear regression and ANOVAs were performed using Statistica version 7.0 with significance set at the .1 level. This significance level was chosen because a $<.05$ significance criterion may be too conservative for detecting important practical changes in the elite sport environment. ${ }^{4,12}$ All data are presented as mean \pm SD unless otherwise stated.

\section{Results}

The mean $( \pm$ SD) Yo-YoIR2 score $(n=43)$ was $1029 \pm$ $185 \mathrm{~m}$ with the median split occurring at $1040 \mathrm{~m}$, and the numbers of interchange rotations for each quarter were Q1 1.4 $\pm 0.6, \mathrm{Q} 21.4 \pm 0.7, \mathrm{Q} 31.2 \pm 0.6$, and Q4 $1.3 \pm 0.7$. There was no significant difference in time on the field for any quarter (Q1 23.8 $\pm 8.1, \mathrm{Q} 224.1 \pm 7.1$, Q3 23.8 \pm 5.4 , and Q4 25.9 $\pm 4.0 \mathrm{~min}$ ). Table 1 indicates the change in match activity measures between quarters and halves, with some variables being significantly different between the first quarter and subsequent quarters and the first and second halves. The weighting of the variables from the multiple-variate regression analysis is presented in Table 2 and indicates the relative importance of the variable in predicting the match exercise-intensity variables across the match.

The greatest difference in all match exercise-intensity indices was between the first and fourth quarters. However, significant differences were only observed in $\mathrm{m} /$ $\mathrm{min}$, HSR $\mathrm{m} / \mathrm{min}$, and LSA $\mathrm{m} / \mathrm{min}$. Only $\mathrm{m} / \mathrm{min}$ and LSA $\mathrm{m} / \mathrm{min}$ were significantly reduced in the second half in the pooled sample (see Table 1). When participants were separated into high $(\mathrm{n}=24)$ and low $(\mathrm{n}=19)$ Yo-Yo IR2 scores, significant differences were observed in $\mathrm{m} / \mathrm{min}$, HSR $\mathrm{m} / \mathrm{min}$, LSA $\mathrm{m} / \mathrm{min}$, and \%HSR in the first quarter and fourth quarter (all variables $P<.01$, respectively; Figure 1). Furthermore, LSA $\mathrm{m} / \mathrm{min}$ and load/min were significantly different between high and low Yo-Yo IR2 groups in the fourth quarter only $(P=.04$ and $P<.01$, respectively). Specifically, HSR $\mathrm{m} / \mathrm{min}$ was reduced in the fourth quarter compared with the first quarter for the high Yo-Yo IR2 group, while the low Yo-Yo IR2 group did not significantly change. However, LSA $\mathrm{m} / \mathrm{min}$ in the low Yo-Yo IR2 group significantly reduced in the fourth quarter compared with the first quarter, while it remained constant in the high Yo-Yo IR2 group.

Table 1 Match Activity Measures for Each Quarter (Q), Pooled Mean ( $90 \%$ Confidence Limits)

\begin{tabular}{|c|c|c|c|c|c|c|}
\hline & Q1 & Q2 & Q3 & Q4 & First half & Second half \\
\hline $\mathrm{m} / \mathrm{min}$ & $\begin{array}{c}141.9, \\
(137.3-146.5)\end{array}$ & $\begin{array}{c}133.7, \\
(129.1-138.3)\end{array}$ & $\begin{array}{c}134.9, \\
(131.3-139.5)\end{array}$ & $\begin{array}{c}129.8, \dagger \\
(125.2-134.4)\end{array}$ & $\begin{array}{c}137.8, \\
(134.5-141.1)\end{array}$ & $\begin{array}{c}132.3,{ }^{*} \\
(129.1-135.6)\end{array}$ \\
\hline HSR $\mathrm{m} / \mathrm{min}$ & $\begin{array}{c}42.5 \\
(39.2-45.9)\end{array}$ & $\begin{array}{c}37.7, \\
(34.4-41.0)\end{array}$ & $\begin{array}{c}39.2 \\
(35.9-42.5)\end{array}$ & $\begin{array}{c}35.1, \dagger \\
(31.8-38.3)\end{array}$ & $\begin{array}{c}40.1 \\
(37.8-42.5)\end{array}$ & $\begin{array}{c}37.1 \\
(34.8-39.5)\end{array}$ \\
\hline LSA $\mathrm{m} / \mathrm{min}$ & $\begin{array}{c}99.4 \\
(97.2-101.6)\end{array}$ & $\begin{array}{c}96.0 \\
(93.8-98.2)\end{array}$ & $\begin{array}{c}95.8 \\
(93.5-98.0)\end{array}$ & $\begin{array}{c}94.7, \dagger \\
(92.5-96.9)\end{array}$ & $\begin{array}{c}97.7 \\
(96.2-99.3)\end{array}$ & $\begin{array}{c}95.2, * \\
(93.7-96.8)\end{array}$ \\
\hline$\% \mathrm{HSR}$ & $\begin{array}{c}29.0 \\
(27.3-30.7)\end{array}$ & $\begin{array}{c}27.3 \\
(25.6-28.9)\end{array}$ & $\begin{array}{c}28.1 \\
(26.4-29.8)\end{array}$ & $\begin{array}{c}26.0 \\
(24.4-29.8)\end{array}$ & $\begin{array}{c}28.1 \\
(26.9-29.2)\end{array}$ & $\begin{array}{c}27.1 \\
(25.8-28.2)\end{array}$ \\
\hline $\mathrm{Load} / \mathrm{min}$ & $\begin{array}{c}16.3, \\
(15.5-17.1) \\
\end{array}$ & $\begin{array}{c}15.3, \\
(14.5-16.1)\end{array}$ & $\begin{array}{c}15.9, \\
(15.1-16.8)\end{array}$ & $\begin{array}{c}15.1, \\
(14.2-15.8)\end{array}$ & $\begin{array}{c}15.8 \\
(15.2-16.4)\end{array}$ & $\begin{array}{c}15.5 \\
(14.9-16.1)\end{array}$ \\
\hline
\end{tabular}

Abbreviations: HSR indicates high-speed running; LSA, low-speed activity.

$\dagger$ Significant difference from 1st quarter at the .1 level. *Significant difference from 1st half at the .1 level. 


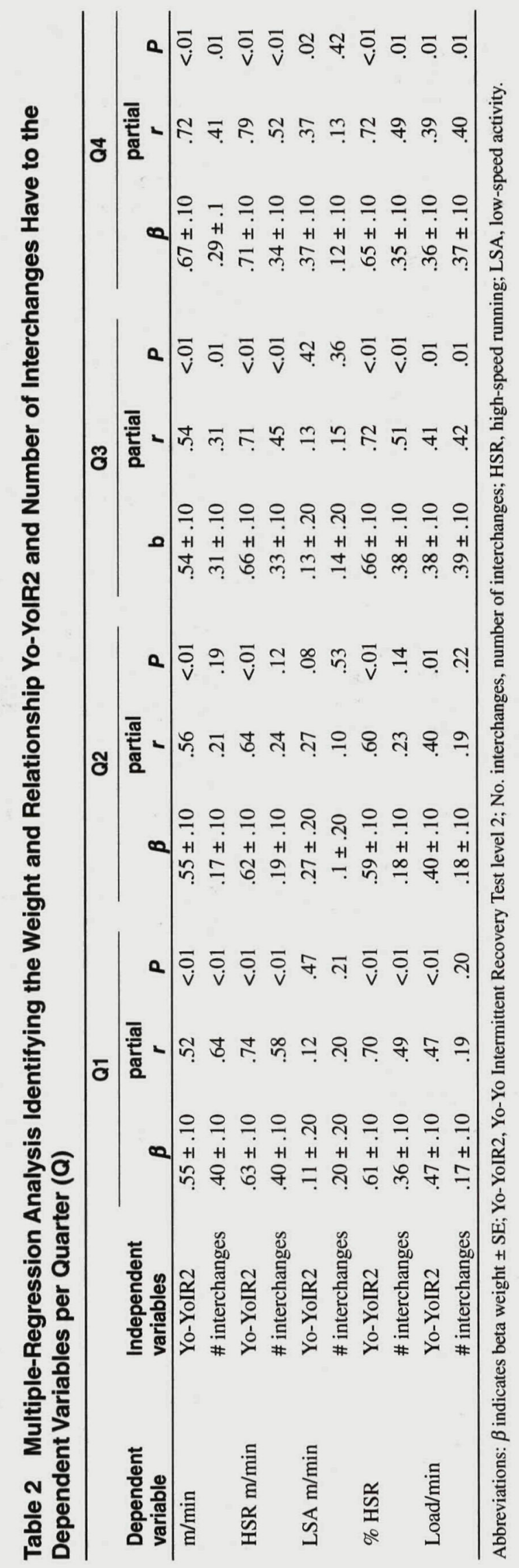


A
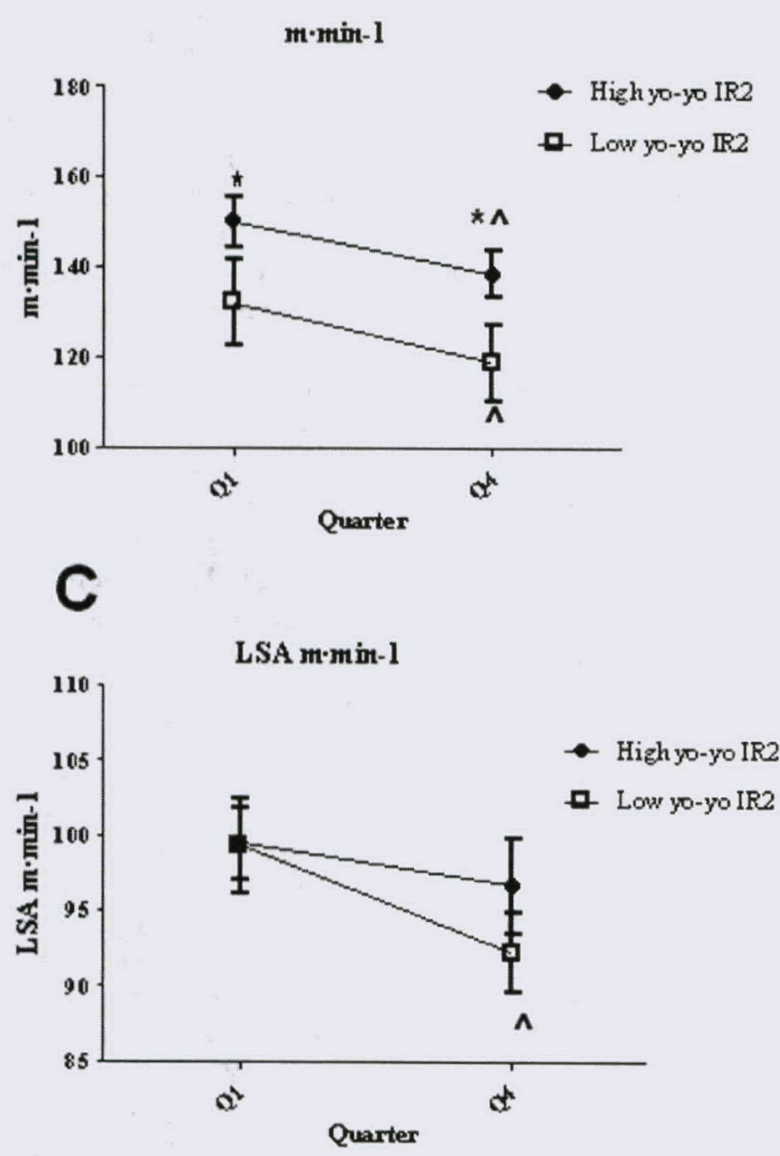

E

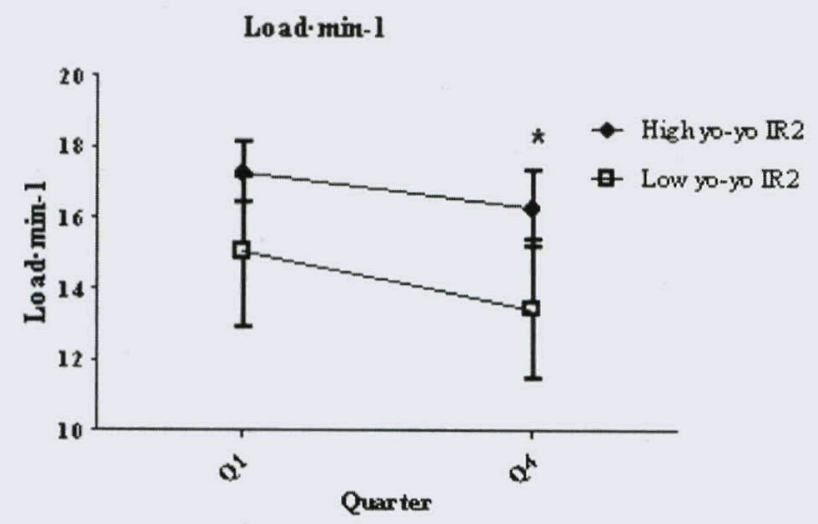

B

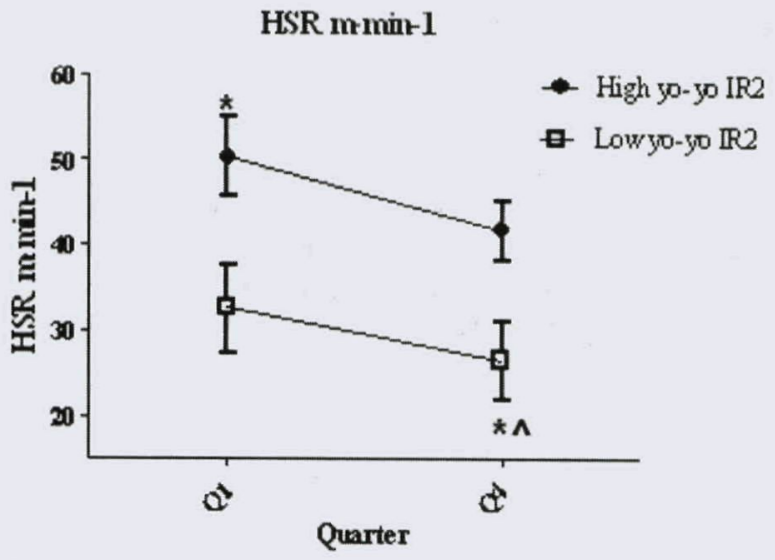

D $\%$ HSR

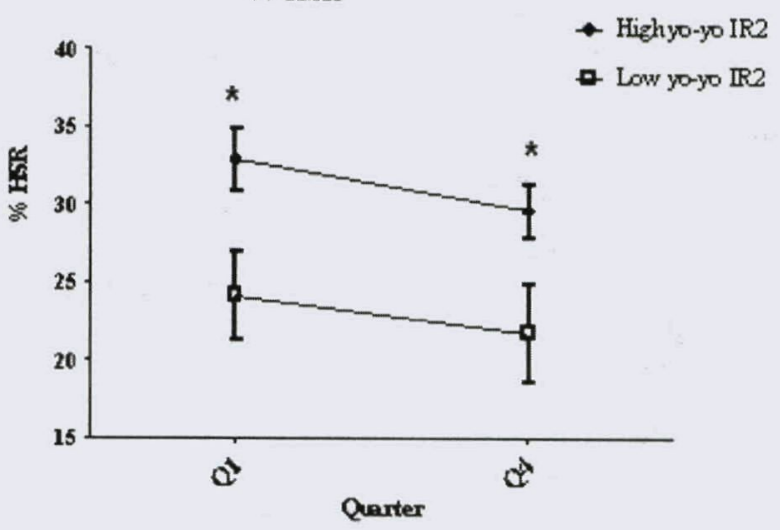

Figure 1 - Graphs identifying the difference between first and fourth quarters (Q1 and Q4) when separated into high and low Yo-Yo Intermittent Recovery Test level 2 scores. (A) $\mathrm{m} / \mathrm{min}$. (B) High-speed running (HSR) $\mathrm{m} / \mathrm{min}$. (C) Low-speed activity $\mathrm{m} / \mathrm{min}$. (D) \% HSR. (E) Load/min. The graphs represent means and error bars represent $90 \%$ confidence limits. *Significant difference at the .1 level between high and low groups. ${ }^{\wedge}$ Significant difference at the .1 level between Q1 and Q4. 
Multivariate linear-regression analysis revealed that Yo-Yo IR2 performance and number of interchanges both significantly contributed to $\mathrm{m} / \mathrm{min}$, HSR $\mathrm{m} / \mathrm{min}$, and \%HSR for all 4 quarters, with the exception of the second quarter, where the number of interchanges was not significantly related (Table 2 ). Yo-Yo IR2 score was significantly related to load/min throughout the entire match, while the number of interchanges was only related in the third and fourth quarters. The number of interchanges did not relate to LSA $\mathrm{m} / \mathrm{min}$ during any quarter. However, Yo-Yo IR 2 significantly contributed to LSA $\mathrm{m} / \mathrm{min}$ in the second and fourth quarters.

\section{Discussion}

This study aimed to determine the degree of change in activity profile during elite Australian football matches and identify the influence of Yo-Yo IR2 performance and number of player interchanges on this profile. The major findings of this study were that there was a significant reduction in $\mathrm{m} / \mathrm{min}$, HSR $\mathrm{m} / \mathrm{min}$, and LSA $\mathrm{m} / \mathrm{min}$ from the first to fourth quarters; that both Yo-Yo IR2 and the number of interchange rotations affect the activity profile of players throughout the match, with Yo-Yo IR2 having the most influence; and higher Yo-Yo IR2 performance has a fatigue-sparing ability from first to fourth quarter. The high Yo-Yo IR2 group performed significantly more $\mathrm{m} / \mathrm{min}$ and HSR $\mathrm{m} / \mathrm{min}$ across the match, and the low Yo-Yo IR2 group performed significantly less LSA in the fourth quarter.

The current results agree with those of previous research that reported a reduction in match exerciseintensity measures across Australian football matches. ${ }^{1,13}$ In particular, we observed that both LSA $\mathrm{m} / \mathrm{min}$ and HSR $\mathrm{m} / \mathrm{min}$ were significantly reduced in the fourth quarter compared with the first quarter $(P=.02$ and .01 , respectively). However, the mean HSR $\mathrm{m} / \mathrm{min} \mathrm{did}$ not significantly change in the second half, whereas the mean LSA $\mathrm{m} / \mathrm{min}$ was reduced in the second half $(P=$ .06). These findings are similar to those of others who found that, in comparison with the first quarter, distance traveled jogging $(7-14.4 \mathrm{~km} / \mathrm{h})$ was reduced as early as the second quarter, while distance of HSR $(>14.4 \mathrm{~km} / \mathrm{h})$ was only reduced in the fourth quarter. ${ }^{1}$ These findings suggest that players may sacrifice distance traveled at low speed to compensate for the demands of HSR, as HSR $\mathrm{m} / \mathrm{min}$ has been linked with superior performance. ${ }^{4}$ Furthermore, players with a higher Yo-Yo IR2 score were able to maintain the amount of LSA better than those with lower Yo-Yo IR2 scores. Indeed, passive recovery allows for greater muscle phosphocreatine (PCr) resynthesis in preparation for a high-intensity effort, so the number of interchanges may explain the differences in the literature. ${ }^{14}$ Other factors such as movement patterns of the opposition, team tactics, and match score may also have influenced the current results.

This study found that the number of interchange rotations affected $\mathrm{m} / \mathrm{min}$, HSR $\mathrm{m} / \mathrm{min}$, and \%HSR in the first, third, and fourth quarters, while significantly influencing load/min in the third and fourth quarters (see Table 2). Notably, LSA m/min was not influenced by the number of interchanges at any stage. This supports the previously mentioned notion that a passive recovery helps maintain HSR throughout an intermittent team sport, but the passive recovery afforded by an interchange rotation appears to have little impact on LSA. Previous studies in soccer have found that the substituting player performs more HSR than other players in the same position on the pitch. ${ }^{15}$ Given that HSR m/ min is important to obtain ball disposals (particularly for nomadic players), the number of interchanges may be important (at least indirectly) to Australian football performance. ${ }^{4}$ To our knowledge this is the first study in Australian football to identify the influence of interchange rotations on match activity profile.

The current results revealed that the capacities assessed by the Yo-Yo IR2 are important qualities that are related to match activities in Australian football, particularly in relation to $\mathrm{m} / \mathrm{min}, \mathrm{HSR} \mathrm{m} / \mathrm{min}$, \%HSR, and load/min. Furthermore, Yo-Yo IR2 performance had a positive influence on LSA $\mathrm{m} / \mathrm{min}$ in the second and fourth quarters. These results suggest that players with a lower Yo-Yo IR2 may rely on modifying their match activity profile to include more passive recovery on the field than players with a higher Yo-Yo IR2. These players may not be suited to being "rested" on the field (eg, midfielders rested in a forward or back pocket) and therefore require more frequent interchanges during the match.

It is likely that players with higher Yo-Yo IR2 have increased physiological capacities that allow faster restoration of $\mathrm{PCr}$ after high-intensity efforts during games. Spencer et a ${ }^{14}$ suggested that $\mathrm{PCr}$ resynthesis may explain the differences in final sprint performance between active and passive recovery during repeatedsprint exercise. As cellular oxygen concentration is known to be a major limiting factor for $\mathrm{PCr}$ resynthesis, ${ }^{14,16}$ this process is likely to be enhanced in Australian football players with a higher Yo-Yo IR2 score due to an improved ability to deliver, extract, and use oxygen during exercise. ${ }^{8,17}$ The addition of breaks between quarters and interchange breaks within the quarter does not appear to allow enough recovery to sustain LSA $\mathrm{m} / \mathrm{min}$ and HSR $\mathrm{m} / \mathrm{min}$. As quarter-time and halftime breaks are of adequate duration (ie, 7.5 and $20 \mathrm{~min}$, respectively) to restore $\mathrm{PCr}$ concentration, an alternative explanation for reduction in match intensity could be the development neuromuscular fatigue that leads to less efficient movement. ${ }^{18,19}$

This study also investigated whether Yo-Yo IR2 level provided any protection from a reduction in match locomotion during Australian football. The $\mathrm{m} / \mathrm{min}$, HSR $\mathrm{m} / \mathrm{min}, \% \mathrm{HSR}$, and load/min variables showed a similar decline from first quarter to fourth quarter in both the high and low groups. This demonstrates that having a high Yo-Yo IR2 score did not prevent a reduction in these match exercise-intensity measures. It was also observed that LSA $\mathrm{m} / \mathrm{min}$ significantly declined from first to 
fourth quarter in the low Yo-Yo IR2 group, suggesting that a higher Yo-Yo IR2 performance may help players maintain LSA during a match. This may allow them to make position (eg, set up in a zone defense or cover an opponent) or make more contests such as ball-ups or throw-ins more effectively. However, in agreement with previous research, ${ }^{1}$ the high Yo-Yo IR2 group did produce significantly greater $\mathrm{m} / \mathrm{min}$, HSR $\mathrm{m} / \mathrm{min}$, and $\%$ HSR in both the first and fourth quarters while also having superior load $/ \mathrm{min}$, suggesting the players with greater capacity produce more distance at high speeds yet are able to maintain the distance covered at lower speeds. $^{1}$

Both Yo-Yo IR2 and number of interchange rotations were found to significantly contribute to the match activity profile of players in elite Australian football. However, this study does not offer a predictive association of match activity profile based on these variables, as match context needs to be considered in much greater detail in terms of playing conditions, team tactics, opposition tactics, score, accumulative fatigue, and positional role. This study does provide empirical evidence that match activity profile can be manipulated tactically through interchange rotations and physically through training (specifically by improving Yo-Yo IR2 performance).

\section{Conclusion}

This study showed that Yo-Yo IR2 score and the number of interchange rest periods during a quarter influence the activity profile of Australian football players. However, Yo-Yo IR2 score does not influence the change in HSR profile from first quarter to fourth quarter. Coaches may choose to enhance players' match exercise intensity by using frequent player interchange. Future studies should focus on the effect of football-specific training on the activity profile of players and the effect of interchange duration and cumulative fatigue on the match activity profile in elite Australian football.

\section{Practical Applications}

- An efficient interchange strategy should be developed to ensure the maintenance of match activity profile.

- Improving the capacities important to the Yo-Yo IR2 should be a focus during preseason preparations, as they enable players to better maintain low-intensity activities during matches.

- Low-speed activities should be monitored during the match, particularly in players with a low Yo-Yo IR2 score.

\section{Acknowledgments}

There was no external funding provided by any organization for this study.

\section{References}

1. Coutts AJ, Quinn J, Hocking J, Castagna C, Rampinini E. Match running performance in elite Australian Rules Football. J Sci Med Sport. 2010;13(5):543-548. PubMed doi:10.1016/j.jsams.2009.09.004

2. Duffield R, Coutts AJ, Quinn J. Core temperature responses and match running performance during intermittent-sprint exercise competition in warm conditions. J Strength Cond Res. 2009;23(4):1238-1244. PubMed doi:10.1519/ JSC.0b013e318194e0b1

3. Aughey RJ. Australian football player work rate: evidence of fatigue and pacing? Int J Sports Physiol Perform. 2010;5(3):394-405. PubMed

4. Mooney M, O'Brien B, Cormack S, Coutts A, Berry J, Young $\mathrm{W}$. The relationship between physical capacity and match performance in elite Australian football: a mediation approach. J Sci Med Sport. 2011;14(5):447-452. PubMed doi:10.1016/j.jsams.2011.03.010

5. Johnston RJ, Watsford ML, Pine MJ, Spurrs RW, Murphy A, Pruyn EC. Movement demands and match performance in professional Australian football. Int J Sports Med. 2012;33(2):89-93. PubMed doi:10.1055/s-0031-1287798

6. Bilzon JL, Allsopp AJ, Williams C. Short-term recovery from prolonged constant pace running in a warm environment: the effectiveness of a carbohydrate-electrolyte solution. Eur J Appl Physiol. 2000;82(4):305-312. PubMed doi:10.1007/s004210000206

7. Buchheit M, Cormie P, Abbiss CR, Ahmaidi S, Nosaka KK, Laursen PB. Muscle deoxygenation during repeated sprint running: effect of active vs. passive recovery. Int J Sports Med. 2009;30(6):418-425. PubMed doi:10.1055/s-0028-1105933

8. Bangsbo J, Iaia FM, Krustrup P. The Yo-Yo Intermittent Recovery Test: a useful tool for evaluation of physical performance in intermittent sports. Sports Med. 2008;38(1):37-51. PubMed doi:10.2165/00007256200838010-00004

9. Krustrup P, Mohr M, Nybo L, Jensen JM, Nielsen JJ, Bangsbo J. The Yo-Yo IR2 Test: physiological response, reliability, and application to elite soccer. Med Sci Sports Exerc. 2006;38(9):1666-1673. PubMed doi:10.1249/01. mss.0000227538.20799.08

10. Jennings D, Cormack S, Coutts AJ, Boyd L, Aughey RJ. The validity and reliability of GPS units for measuring distance in team sport specific running patterns. Int $J$ Sports Physiol Perform. 2010;5(3):328-341. PubMed

11. Boyd LJ, Ball K, Aughey RJ. The reliability of mini$\max \mathrm{X}$ accelerometers for measuring physical activity in Australian football. Int J Sports Physiol Perform. 2011;6(3):311-321. PubMed

12. Batterham AM, Hopkins WG. Making meaningful inferences about magnitudes. Int J Sports Physiol Perform. 2006;1(1):50-57. PubMed

13. Duffield R, Coutts A, Quinn J. Core temperature responses and match running performance during intermittent sprint condition in warm conditions. $J$ Strength Cond Res. 2009;23(4):1238-1244. PubMed doi:10.1519/ JSC.0b013e318194e0b1 
14. Spencer M, Bishop D, Dawson B, Goodman C, Duffield R. Metabolism and performance in repeated cycle sprints: active versus passive recovery. Med Sci Sports Exerc. 2006;38(8):1492-1499. PubMed doi:10.1249/01. mss.0000228944.62776.a7

15. Carling C, Espie V, Le Gall F, Bloomfield J, Jullien H. Work-rate of substitutes in elite soccer: a preliminary study. J Sci Med Sport. 2010;13(2):253-255. PubMed doi:10.1016/j.jsams.2009.02.012

16. Glaister M. Multiple sprint work: physiological responses, mechanisms of fatigue and the influences of aerobic fitness. Sports Med. 2005;35(9):757-777. PubMed doi:10.2165/00007256-200535090-00003
17. Tomlin DL, Wenger HA. The relationship between aerobic fitness and recovery from high intensity intermittent exercise. Sports Med. 2001;31(1):1-11. PubMed doi:10.2165/00007256-200131010-00001

18. Noakes TD. The physiological models to understand exercise fatigue and adaptations that predict or enhance athletic performance. Scand J Med Sci Sports. 2000;10:123-145. PubMed doi:10.1034/j.1600-0838.2000.010003123.x

19. Mooney MG, Cormack S, O'Brien BJ, Morgan WM, McGuigan M. Impact of neuromuscular fatigue on match exercise intensity and performance in elite Australian football. J Strength Cond Res. 2013;27(1):166-173. PubMed doi:10.1519/JSC.0b013e3182514683 
Copyright of International Journal of Sports Physiology \& Performance is the property of Human Kinetics Publishers, Inc. and its content may not be copied or emailed to multiple sites or posted to a listserv without the copyright holder's express written permission. However, users may print, download, or email articles for individual use. 